\title{
What can Medicaid data add to research on VA patients?
}

\author{
Ann Hendricks, PhD; ${ }^{1-2 *}$ John Gardner, PhD; ${ }^{1}$ Austin Frakt, PhD; ${ }^{1-2}$ Daniel Gilden, MS; ${ }^{3}$ Julia Prentice, \\ PhD; ${ }^{1-2}$ Lynn Wolfsfeld, MPP; ${ }^{1}$ Steven Pizer, PhD $^{1-2}$ \\ ${ }^{1}$ Health Care Financing and Economics, Department of Veterans Affairs Boston Healthcare System, Boston, MA; \\ ${ }^{2}$ Department of Health Policy and Management, School of Public Health, Boston University, Boston, MA; ${ }^{3} \mathrm{JEN}$ \\ Associates, Cambridge, MA
}

\begin{abstract}
This article is the first to describe Department of Veterans Affairs (VA) patients' use of Medicaid at a national level. We obtained 1999 national VA enrollment and utilization data, Centers for Medicare and Medicaid Services enrollment and claims, and Medicare information from the VA Information Resource Center. The research team created files for program characteristics and described the VA-Medicaid dually enrolled population, healthcare utilization, and costs. In 1999, VA-Medicaid dual enrollees comprised $10.2 \%$ of VA's annual patient load (350,000/3,450,000); 304,000 were veterans. These veterans differed marginally from VA's veteran patients, being on average half a year younger and having $1 \%$ fewer males. Dual enrollees with mental health diagnoses and care were almost three times as numerous as long-term care patients; these two groups accounted for $\sim 60 \%$ of dual enrollees. Dual enrollees disproportionately included housebound veterans and veterans needing aid and assistance. Half the dual enrollees had 12 months of Medicaid eligibility, and total Federal expenditures per patient not in managed care programs averaged $>\$ 18,000$ (median $>\$ 6,000$ ). Dually enrolled women veterans cost $\sim 55 \%$ less than men. Medicaid benefits complement VA and are more accessible in many states. VA researchers need to consider including Medicaid utilization and costs in their studies if they target populations or programs related to long-term care or mental disorders.
\end{abstract}

Key words: costs, data quality, disability, healthcare utilization, long-term care, Medicaid, Medicare, mental health, veterans, vulnerable populations.

\section{INTRODUCTION}

The Department of Veterans Affairs (VA) has increasingly recognized the importance of the Medicare program to its patient population [1]. In 1999, 53 percent of VA patients were also enrolled in Medicare [2], and that proportion has grown as the veteran population has aged. VA patients' reliance on Medicare varies widely, but in any given year, almost two-thirds of VA-Medicare dually enrolled veterans use some services paid for through the Medicare program. The role of Medicaid, a health insurance program for low-income and disabled individuals that is run as a Federal-state partnership, has been examined for only a few subpopulations of VA patients [3-5]. This article complements the literature on VA-Medicare dual use and documents the importance of the Medicaid program for VA patients with or without Medicare enrollment status.

\footnotetext{
Abbreviations: CMS $=$ Centers for Medicare and Medicaid Services, $\mathrm{CY}=$ calendar year, HERC $=$ Health Economics Resource Center, MAX = Medicaid Analytic Extract, MSIS = Medicaid Statistical Information System, VA = Department of Veterans Affairs, VIReC = VA Information Resource Center.

*Address all correspondence to Ann Hendricks, PhD; Boston VA-Health Care Financing and Economics, 150 South Huntington Avenue (152H), Boston, MA 02130; 857-3646015; fax: 857-364-4511. Email: ann.hendricks@med.va.gov DOI:10.1682/JRRD.2009.07.0107
} 
Reasons for the lack of research on dually enrolled VAMedicaid veterans include the lack of national Medicaid data before 1999, lags in data availability, and the relatively small proportion of VA patients who are enrolled in Medicaid. The Medicaid Statistical Information System (MSIS), covering virtually all 50 states beginning in 1999, allows examination of patient-level Medicaid expenditures across the country, removing one barrier for VA researchers.

This article is the first to capitalize on the nationallevel MSIS data to describe the veteran population dually enrolled in VA and Medicaid and to examine the issues that arise when reconciling VA and Medicaid data. Our goals in this article are to (1) describe the VA-Medicaid dual enrollee population, (2) establish the import of the Medicaid programs for VA patients, and (3) document issues and solutions for VA researchers interested in using Medicaid data in the future.

\section{ANALYTIC FILE CONSTRUCTION}

Under a data-use agreement with the Centers for Medicare and Medicaid Services (CMS), we obtained nine quarters of MSIS eligibility and utilization files (for calendar years [CYs] 1999 and 2000 plus the first quarter of 2001) for the country as a whole. We matched enrollees in the MSIS files to a finder file of all 8.3 million VA patients with any VA utilization at the national level from 1995 to 2001, with no exclusions. We then extracted the Medicaid claims and enrollment records for service dates in either CY1999 or CY2000 to obtain the Medicaid utilization and enrollment data for analysis. This established our population of VA-Medicaid dual enrollees.

We sent the file of VA-Medicaid dual enrollees' study identification numbers to the VA Information Resource Center (VIReC) to match against a master file of VAMedicare dual enrollees. VIReC extracted Medicare eligibility and utilization records for these triply enrolled veterans for the project's analyses.

A major challenge when merging data on veterans from three separate data sets is the reconciliation of conflicting information. For example, decisions are necessary to assign a state of residence for each patient. This is an issue because Medicaid benefits, which affect whether veterans qualify for enrollment and what services they get, vary across states. VA, Medicare, and Medicaid may all list a patient's residence as being in a different state during a given year, although 88 percent of all the dual enrollees in our study had only one state of residence listed across all programs.

We determined enrollees' states of residence by using Medicaid enrollment records, except for those patients with equal numbers of months in two different state programs. In these relatively few $(<200)$ cases, we based residence on Medicare and then VA utilization data for 1999. Reconciling differences across the programs with respect to patient age, race, and other variables is described by Gardner et al. [6].

Another challenge is the identification of financial amounts that are comparable across programs. We used program expenditures for VA, Medicaid, and Medicare. For the latter two programs, expenditures were identified as payments in the claims for care. For VA, expenditures for each type of service were encounter-based costs that VA's Health Economics Resource Center (HERC) estimated by applying Medicare-based relative values to each recorded outpatient procedure code and each medical or surgical inpatient episode (adjusted for lengths of stay) and then multiplying the value units by a dollar conversion factor based on VA's total budget for each type of care [7-11]. HERC estimated nursing home stays in 1999 by using per diems [12]. HERC estimates are comparable to Medicare and Medicaid expenditures because the service units tend to have the same relative value units.

Similarly, we used national prescription drug costs that VA's Decision Support System estimated by using a shelf price and standard dispensing cost. Researchers should examine these costs carefully for negative values (generally reflecting returned drugs) and unreasonably high values, which may be errors in the units of drugs used to calculate an average cost per dose.

Patient out-of-pocket expenditures posed a separate challenge. Each program charges at least some patient deductibles or copayments, but each treats these out-ofpocket expenses differently. VA does not distinguish copayments made by patients for medications and healthcare services from expenditures made by VA medical centers. Both Medicare and Medicaid list these liabilities in the claims but not whether they were paid. For comparability, we calculated Medicaid and Medicare expenditures as the total amount each program allowed as payment, whether actually paid by the program, the patient, or another payer (e.g., supplemental insurance).

Medicare Advantage (i.e., Medicare managed care) enrollees accounted for 4.8 percent of the VA-Medicaid veteran population of 304,000 . The proportion of the 
veterans enrolled in Medicaid managed care plans was 26.2 percent of the total VA-Medicaid dual-enrollee population (excluding plans for dental or prenatal care, which included only a few hundred VA patients). Only 0.6 percent of dual enrollees were enrolled in both Medicare and Medicaid managed care plans. We have included all 30.5 percent in the population descriptions that follow (Tables 1-3) but excluded them from the estimates of expenditures (Table 4), because we could not estimate payments by each state for those enrolled.

Finally, studies of VA patients enrolled in regular state Medicaid programs must consider differences in benefit plans and eligibility requirements in order to understand differences in patterns of veterans' enrollment and utilization of the programs. A data set that was created as part of this project and includes information on Medicaid eligibles, beneficiaries, and payments by state and year is available from 1997 to 2002 for download and unrestricted public use from our VA Web site [13].

\section{RESULTS}

\section{VA-Medicaid Dual-Enrollee Population}

We identified 441,274 people who had been VA patients at any time between 1995 and 2001 and who were enrolled in Medicaid at least one month in CY1999 or CY2000. Using multiple years of data permits identification of VA patients who may not utilize services in both systems in a given year but move between the systems as their situations warrant. After excluding records for patients who had died before the start of 1999, we deemed a total of 440,124 people to have been dually enrolled during the study years. Of these, almost 88 percent $(386,229)$ were veterans (Table 1). The nonveterans were likely active military personnel or dependents of either veterans or active military, who can access VA services under several benefits, such as CHAMPVA or TRICARE. The number of VA-Medicaid dual enrollees who were veterans was

Table 1.

Number of Department of Veterans Affairs-Medicaid dual enrollees by year(s) and veteran status.

\begin{tabular}{lrcr}
\hline Year(s) in Medicaid & Veterans & Nonveterans & \multicolumn{1}{c}{ Total } \\
\hline 1999 Only & 79,381 & 13,579 & 92,960 \\
Both 1999 and 2000 & 225,340 & 32,518 & 257,858 \\
2000 Only & 81,508 & 7,798 & 89,306 \\
\hline Total & 386,229 & 53,895 & 440,124 \\
\hline \hline
\end{tabular}

fairly stable between the 2 years. The number of nonveteran VA patients covered through Medicaid declined about 13 percent in 2000 .

The remainder of this article focuses only on the veterans eligible for both VA and Medicaid services. This article presents information only for the 1999 dual enrollees (from Table 1: 225,340 + 79,381 = 304,721), the group for whom we have the most complete Medicaid utilization data, but is representative of both years.

The VA-Medicaid population differs from the larger VA patient population only marginally in terms of demographic characteristics (Table 2). It has about 1 percent fewer males and is half a year younger on average, with about 42 percent of dually enrolled veterans 65 years or older compared with 44 percent of all veterans in VA in 1999. The VA-Medicaid dual enrollees were also more likely than all VA patients to be enrolled in Medicare (61\% vs 53\%). The VA patients enrolled in Medicaid plus Medicare differed markedly from those not triply enrolled in that they were older (mean age 67 vs 49 ), were more likely to be male ( $97 \%$ vs $90 \%$ ), and had longer enrollments in Medicaid (more than half had been in Medicaid all year). The large number of dually enrolled veterans means that the differences summarized here are all likely to be statistically significant.

\section{Physical Disability and Mental Illness in VA-Medicaid Population}

Many providers associate Medicaid enrollment with older adults in nursing homes, and our prior expectation was that VA-Medicaid dual enrollees would primarily (more than 50\%) be nursing home patients. This scenario fits the image of VA long-term care as providing a "bridge" as the veterans spend down and qualify for Medicaid coverage [14]. However, our description of the population suggests that veterans can qualify for Medicaid coverage in many ways, including disability (not necessarily related to military service). In general, VA-Medicaid enrolled veterans were eligible for Medicaid because they were "blind/ disabled” ( 45\%) or “aged” ( 38\%) (data not shown). Most of the other dually enrolled veterans qualified as "adult" or "unemployed adult."

VA priority status provides another measure of disability. About 10 percent of dually enrolled veterans had no VA priority status in the available enrollment file, a VA data issue that will have declined for more recent years (Table 2). Of those with a status listed, the dually enrolled were much less likely than VA patients in general to have a service-connected disability, indicated by Priority 1-3 
JRRD, Volume 47, Number 8, 2010

Table 2.

Demographic characteristics of veterans dually enrolled in Department of Veterans Affairs (VA) and Medicaid, 1999.

\begin{tabular}{|c|c|c|c|c|}
\hline \multirow[b]{2}{*}{ Characteristic } & \multicolumn{3}{|c|}{ VA-Medicaid Dual Enrollees } & \multirow{2}{*}{$\begin{array}{l}\text { All VA Patients } \\
\text { ( } N=3.45 \text { million })\end{array}$} \\
\hline & $\begin{array}{c}\text { Total } \\
(n=304,721)\end{array}$ & $\begin{array}{c}\text { Medicaid Only, } \\
1999\end{array}$ & $\begin{array}{c}\text { Medicare \& } \\
\text { Medicaid, } 1999\end{array}$ & \\
\hline Total (\%) & 100.0 & 39.4 & 60.6 & \\
\hline Male (\%) & 93.5 & 90.1 & 96.7 & 95.2 \\
\hline \multicolumn{5}{|l|}{ Age } \\
\hline$<45$ yr (\%) & 18.8 & 31.4 & 7.8 & \\
\hline 45-64 yr (\%) & 39.1 & 64.6 & 24.5 & \\
\hline >64 yr (\%) & 41.8 & 3.9 & 67.8 & 44.5 \\
\hline Mean & 59.3 & 49.3 & 66.9 & 59.9 \\
\hline \multicolumn{5}{|l|}{ Priority Group (\%) } \\
\hline 1-3: Service-Connected Disabled & 19.4 & 22.3 & 17.2 & 35.2 \\
\hline 4 or 6: Housebound or Former POW & 15.1 & 10.6 & 18.6 & 4.4 \\
\hline 5: Low-Income & 51.9 & 56.1 & 48.7 & 46.7 \\
\hline 7-8: Other & 3.5 & 5.0 & 2.3 & 12.7 \\
\hline Unknown & 10.1 & 6.0 & 13.2 & \\
\hline Medicare Enrolled (\%) & 60.6 & 0 & 100.0 & 52.7 \\
\hline Medicaid Enrollment (mean months) & 8.6 & 8.2 & 9.0 & NA \\
\hline Enrolled in Medicaid 12 Months (\%) & 48.2 & 42.0 & 53.2 & \\
\hline
\end{tabular}

Note: Priority numbers reflect 1999 priority categories.

*Proportions from Shen et al. [1]. Number of VA patients (calculated by authors) includes those veterans with VA-paid care purchased from private-sector providers. 1. Shen Y, Hendricks A, Zhang S, Kazis LE. VHA enrollees’ health care coverage and use of care. Med Care Res Rev. 2003;60(2):253-67. DOI:10.1177/1077558703060002007

NA $=$ not available, $\mathrm{POW}=$ prisoner of war

(19\% vs 35\%, respectively), and more likely to have lowincome Priority 5 status (52\% vs $47 \%$, respectively). A disproportionate number (15\% of VA patients in Medicaid were Priority 4 (housebound/catastrophically disabled) and Priority 6 (former prisoner-of-war) as compared with the overall VA patient population (4.4\%). (Priority numbers reflect 1999 priority categories).

Almost half (48\%) of the VA-Medicaid dual enrollees had a full 12 months of Medicaid eligibility in 1999. The primary categories under which they qualified for Medicaid coverage were "aged" and "blind/disabled" (data not shown). Only 11,335 (about 3\%) of the dually enrolled veterans qualified under more than one eligibility category in the year.

A major category of disability for veterans is mental illness. The number of dual enrollees with a mental illness diagnosis was more than 100,000 (out of 304,721 total), but the majority did not fall into the group considered as having serious mental illnesses (see Table 3, which lists the diagnoses used to identify this population).

Table 3 shows descriptive statistics on several main subpopulations of VA-Medicaid dual enrollees. These subpopulations vary in age, VA priority status, short-term mortality, and Medicare enrollment. On average, those receiving long-term care (which includes home care visits) were oldest, most likely to be housebound (Priority 4) and least likely to qualify for VA care because of low income (Priority 5). Many more of them died in 1999.

\section{Public Cost of Dual Enrollees}

In 1999, VA served 3.45 million patients with a medical care budget of $\$ 17.7$ billion. The average annual VA expense per patient was therefore about $\$ 5,120$. Dually enrolled veterans (excluding those in managed care) were markedly more costly (at $\$ 18,171$ for men and $\$ 10,646$ for women) to the U.S. taxpayer (Table 4) but not necessarily through the VA benefit. Table 4 underscores that the expenditures per patient for all three publicly funded health programs were highly skewed. For example, the mean values for total costs were roughly 3 times the median amounts and the mean costs of outpatient drugs were 7 to 14 times the median prescription costs.

Across the three public programs, mean and median costs were higher for men than women. The annual mean 
Table 3.

Characteristics of Department of Veterans Affairs (VA)-Medicaid dual enrollees in long-term care (LTC) or with mental illness diagnoses, 1999.

\begin{tabular}{|c|c|c|c|c|c|}
\hline Characteristic & $\begin{array}{l}\text { Received } \\
\text { LTC }^{*}\end{array}$ & $\begin{array}{c}\text { Serious Mental } \\
\text { Illness }^{\dagger}\end{array}$ & $\begin{array}{l}\text { Other Mental } \\
\text { Illness }\end{array}$ & $\begin{array}{c}\text { Only Substance } \\
\text { Abuse }^{\S}\end{array}$ & $\begin{array}{c}\text { None of } \\
\text { Preceding }\end{array}$ \\
\hline No. & 47,882 & 37,130 & 97,329 & 1,207 & 121,173 \\
\hline Male (\%) & 97.1 & 91.1 & 93.9 & 95.6 & 92.3 \\
\hline \multicolumn{6}{|l|}{ Priority Group (\%) } \\
\hline 1-3: Service-Connected Disabled & 19.5 & 19.5 & 21.6 & 15.5 & 17.7 \\
\hline 4 or 6: Housebound or Former POW & 30.6 & 22.7 & 13.1 & 7.6 & 8.4 \\
\hline 5: Low-Income & 22.8 & 49.3 & 54.4 & 67.9 & 62.0 \\
\hline 7-8: Other & 2.6 & 2.8 & 2.9 & 4.2 & 4.5 \\
\hline Unknown & 24.6 & 5.7 & 8.1 & 4.8 & 7.4 \\
\hline Died in 1999 (\%) & 21.6 & 2.2 & 4.5 & 2.5 & 5.0 \\
\hline Medicare Enrolled in 1999 (\%) & 86.1 & 54.4 & 48.3 & 34.0 & 52.4 \\
\hline \multicolumn{6}{|l|}{ Age in 1999} \\
\hline Mean & 72.7 & 50.3 & 56.0 & 52.1 & 59.4 \\
\hline Median & 72.0 & 48.0 & 54.0 & 50.0 & 62.0 \\
\hline Medicare Enrolled in 2000 (\%) & 70.4 & 80.6 & 75.6 & 69.4 & 71.8 \\
\hline Enrolled in Medicaid 12 Months (\%) & 47.1 & 55.2 & 48.3 & 42.2 & 48.8 \\
\hline
\end{tabular}

Note: Priority numbers reflect 1999 priority categories.

${ }^{*}$ LTC measure: Patients in VA domiciliaries or nursing homes, Medicaid patients in nursing or intermediate care facilities, and psychiatric hospitals/wards; Medicare patients with claims for skilled nursing facilities, hospice, and home health.

${ }^{\dagger}$ International Classification of Diseases-9th edition (ICD-9) codes 295.0-295.9 except 295.5, 296.x, 309.81 (schizophrenia, bipolar disorder, posttraumatic stress disorder [PTSD], and major depression).

${ }^{\ddagger}$ VA patients with ICD-9 codes 290-319 (excluding those above); Current Procedural Terminology codes for treatment (90813-90829, 90845-90848, 90853, 90857) without associated ICD-9 codes for serious mental illness; VA clinic stops for PTSD; in Medicaid, includes place of service codes for mental health; diagnosis-related groups (DRGs) 424-432 without above diagnoses; in psychiatric bedsection (33, 38, 70-71, 78-79, 89, 91-93) or clinic (502-503, 509-510, 512, 516, 532, 540, 550, $552,557-558,559,562,574,576-578,580-581,731)$ without serious mental illness.

§ICD-9 codes for abuse of alcohol (291.0-291.5, 291.81, 303.0, 303.9, 305.0) or drugs (304.0-304.9, 305.2-305.9, 292.0) but no mental illness diagnoses; Bedsection 72 (alcohol high intensity) or 73 (high intensity drug abuse), clinical stop 523 (methadone); DRGs 433-437 or bedsections 27, 29, 37, 74, and 90; or clinical stops 513, 514, 519, 560 without above diagnoses.

POW = prisoner of war.

Table 4.

Total public expenditures for Department of Veterans Affairs (VA)-Medicaid dually enrolled veterans not in managed care programs, 1999.

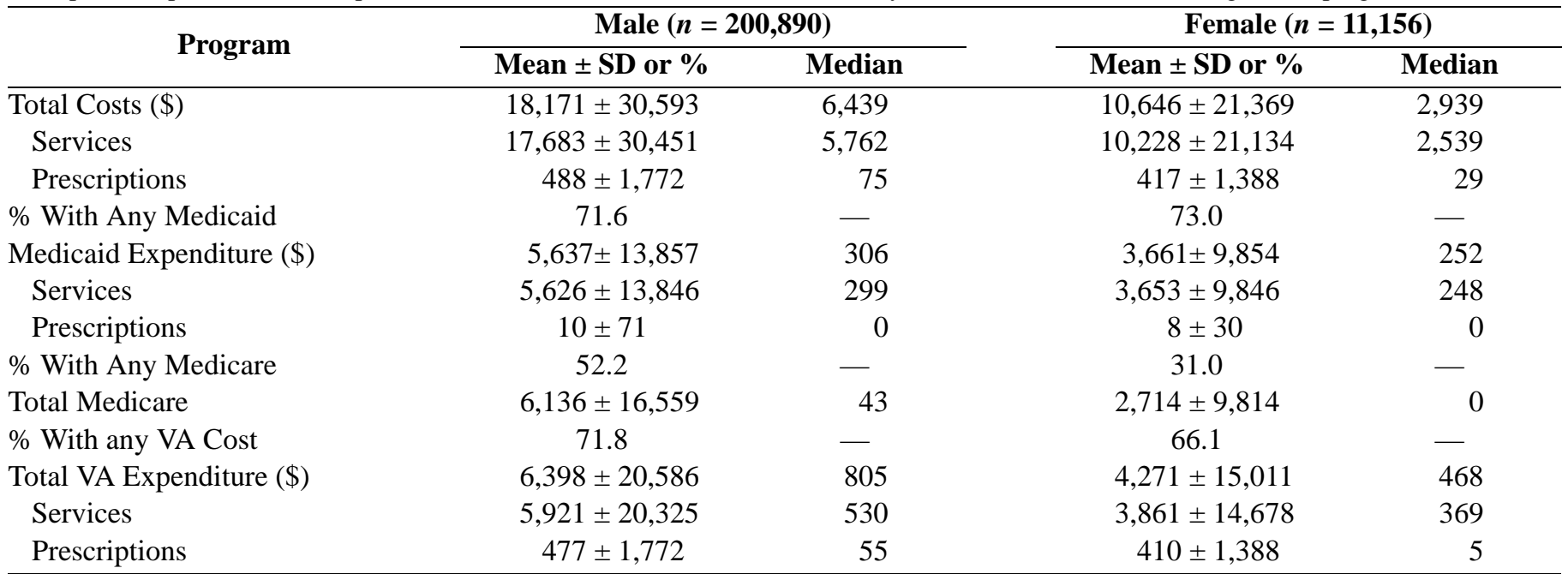

${ }^{*}$ Managed care programs included Medicare Advantage ( $<5 \%$ of all VA-Medicaid dual enrollees) or any Medicaid managed care other than that for prenatal care or dental care (26.2\% of all VA-Medicaid dual enrollees including $0.6 \%$ also enrolled in Medicare Advantage).

$\mathrm{SD}=$ standard deviation. 
total for men was $\$ 18,171$ compared with only $\$ 10,646$ for women (median \$6,439 for men and \$2,939 for women). Almost all the higher cost for men was due to their greater use of services, not medications.

The mean cost of total prescriptions was $\$ 488$ for men and $\$ 417$ for women. For both sexes, 98 percent of average prescription cost was paid through VA. In 1999, no Medicare prescription drug coverage was available, except through managed care plans, whose members were excluded from Table 4.

For patients of both sexes, average VA expenditures were highest (\$6,398 for men, $\$ 4,271$ for women). For men, average Medicare expenditures $(\$ 6,136)$ were somewhat higher than mean Medicaid outlays $(\$ 5,637)$; for women, the opposite was true, with average Medicaid expenditures $(\$ 3,661)$ almost 25 percent higher than those for Medicare, (\$2,714).

Dually enrolled women veterans were also much less likely to use Medicare programs than the men (22\% vs $44 \%$, respectively). This is undoubtedly due to the fact that the women were 16 years younger than the men on average (44 vs 60 years in 1999, data not shown).

The expenditures shown in Table 4 include only those dually enrolled veterans who were not in Medicare or Medicaid managed care plans. However, the 30 percent of this population in those behavioral health or medical care plans were almost as costly to VA as those who were not in managed care. For example, men in Medicaid plans averaged \$5,241 in VA expenditures in 1999 (data not shown) compared with the $\$ 6,398$ for those without managed care; dually enrolled women in Medicaid plans averaged \$2,737 in total VA costs compared with $\$ 4,271$ for those without such managed care.

\section{DISCUSSION AND CONCLUSIONS}

Research questions and study population determine how important it is for VA researchers to add Medicaid data to their study. Veterans dually enrolled in VA and Medicare comprise the majority of VA patients. The overlap between Medicaid and VA enrollment is far less; 10.2 percent of VA patients in 1999 (350,000 out of 3.45 million) were also Medicaid enrollees if dual enrollees without VA utilization that year are counted. Consequently, depending on the study, VA researchers may not need to include Medicaid utilization and costs in their analyses.
However, Medicaid utilization is essential to consider for certain populations. As expected, enrollment in Medicaid was important for frail elderly veterans needing nursing home care. The dually enrolled population also disproportionately included housebound VA patients and those needing aid and assistance or mental health care services. For these populations, Medicaid care may be important, not only as a total expense to the taxpayer but also in terms of providing considerable services to the patients, almost half of whom were eligible for Medicaid because they were blind or disabled according to Medicaid criteria, which necessarily differ by state. The Medicaid claims records can provide additional diagnoses, identify sentinel events, or indicate prescriptions.

Medicaid claims may not add new utilization information for many VA-Medicaid patients also enrolled in Medicare. For some patients, the Medicaid claims often did not identify new inpatient care, because the Medicaid programs were generally secondary payers to Medicare and the Medicare claims included inpatient acute services [15]. About 40 percent of the VA-Medicaid dual enrollees were not in Medicare, however, and for these patients, the Medicaid claims are an important source of information about sentinel events such as non-VA emergent and inpatient acute care.

While this study used MSIS data, VA researchers interested in Medicaid data will rely on Medicaid Analytic Extract (MAX) files in the future. CMS compiles the MAX files from paid claims across seven quarters for each quarter of services and imposes some data quality standards on the state files. The main difference between VA utilization data and MAX files is that data on diagnoses, services, and expenditures in the MAX files accumulate as the claims are paid by the program. This process requires a 2-year or more lag in availability, a major disadvantage to their use.

This project used the MSIS data before the MAX extracts were available, allowing us to examine the completeness of the MAX files. The MAX extract for each quarter of services in a CY includes claims with service dates in that quarter but payment dates in that or any of the following six quarters. In general, we found that the MAX data had 98 to 99 percent of all the services captured in a full nine quarters of MSIS data and will save the researcher considerable time in compiling the data. VIReC (www.virec.research.va.gov) makes Medicaid data from 1999 onward available to VA researchers with approved research projects. With data sets at VIReC, checking for dual enrollment should be a minimal step for retrospective 
studies on long-term care patients and patients with mental health diagnoses or conditions requiring aid and assistance.

Studies of VA patients enrolled in regular state Medicaid programs must consider differences in benefit plans and eligibility requirements in order to understand differences in patterns of veterans' enrollment and utilization of the programs. A data set that was created as part of this project and includes information on Medicaid eligibles, beneficiaries, and payments by state and year is available from 1997 through 2002 [13]. Some analyses may be able to use this information to describe the relative differences across states included in their studies. Our project also used a method of summarizing Medicaid eligibility policy differences based on the Medicaid/private insurance "crowd-out" literature of the past 15 years [16-19]. This approach was useful in an analysis of the impact of fragmented financing on health outcomes for VA patients [20].

One limitation of this analysis was the use of data from 1999, the only complete year available for the study. Since then, the number of VA enrollees has grown from 3.45 million to 5.5 million. If the additional patients are less likely to be Medicaid enrollees, the impact of Medicaid utilization data will be less than shown here. If they are more likely, due to frailty and low income, the impact will be greater.

Finally, these data sets share many shortcomings common to claims or administrative utilization data sets: not all diagnoses or problems are captured, vital signs are missing, and coding may be biased toward payment algorithms. Despite the shortcomings, Medicaid claims are essential for certain veteran populations, such as those experiencing mental illness or in long-term care. Therefore, VA researchers should consider whether their research questions require supplemental Medicaid data.

\section{ACKNOWLEDGMENTS}

\author{
Author Contributions: \\ Study concept and design: A. Hendricks, S. Pizer. \\ Acquisition of data: D. Gilden, L. Wolfsfeld. \\ Creation of analytic variables: A. Frakt. \\ Analysis and interpretation of data: A. Hendricks, J. Prentice. \\ Interpretation of results: A. Frakt. \\ Statistical analysis and interpretation: J. Gardner. \\ Drafting of manuscript: A. Hendricks. \\ Review of manuscript for important statistical content: J. Gardner. \\ Review of manuscript for correct interpretation related to quality of \\ data: A. Frakt. \\ Critical review of manuscript for health services content: J. Prentice.
}

Critical review of manuscript for important policy and data content:

S. Pizer.

Critical review of manuscript for policy content: L. Wolfsfeld.

Critical review of manuscript for quality of Medicaid data: D. Gilden. Administrative support: L. Wolfsfeld.

Technical support in use of Medicaid data and state differences in policy: D. Gilden.

Study supervision: A. Hendricks.

Financial Disclosures: The authors have declared that no competing interests exist.

Funding/Support: This material was based on work supported by VA Office of Research and Development, Health Services Research and Development Service (grant IIR 03-199).

Additional Contributions: The opinions expressed in this article are the authors' and do not reflect those of the VA, Veterans Health Administration, or Health Services Research and Development Service.

Institutional Review: The institutional review board of the VA Boston Healthcare System approved this study protocol.

\section{REFERENCES}

1. Fleming C, Fisher ES, Chang CH, Bubolz TA, Malenka DJ. Study outcomes and hospital utilization in the elderly: The advantages of a merged data base for Medicare and Veterans Affairs hospitals. Med Care. 1992;30(5):377-91.

[PMID: 1583916]

DOI:10.1097/00005650-199205000-00001

2. Shen Y, Hendricks A, Zhang S, Kazis LE. VHA enrollees' health care coverage and use of care. Med Care Res Rev. 2003;60(2):253-67. DOI:10.1177/1077558703060002007

3. Desai RA, Rosenheck RA. The impact of managed care on cross-system use of mental health services by veterans in Colorado. Psychiatr Serv. 2002;53(12):1599-1604.

[PMID: 12461222]

DOI:10.1176/appi.ps.53.12.1599

4. Jia H, Zheng Y, Reker DM, Cowper DC, Wu SS, Vogel WB, Young GC, Duncan PW. Multiple system utilization and mortality for veterans with stroke. Stroke. 2007;38(2): 355-60. [PMID: 17194888] DOI:10.1161/01.STR.0000254457.38901.fb

5. Gardner J, Hendricks A. VA long-term care patients' Medicare and Medicaid expenditures. Washington (DC): Department of Veterans Affairs; 2004. HCFE Data Brief No.: 2004-05.

6. Gardner JA, Hendricks AM, Wolfsfeld L. Technical documentation: Medicaid enrollment, utilization and outcomes for VA patients. Washington (DC): Department of Veterans Affairs; 2008. HCFE Data Brief No.: 2008-01.

7. Barnett PG. Determination of VA health care costs. Med Care Res Rev. 2003;60(3 Suppl):124S-41S. [PMID: 15095549] DOI:10.1177/1077558703256483

8. Wagner TH, Chen S, Barnett PG. Using average cost methods to estimate encounter-level costs for medical-surgical 
JRRD, Volume 47, Number 8, 2010

stays in the VA. Med Care Res Rev. 2003;60(3 Suppl): 15S-36S. [PMID: 15095543] DOI:10.1177/1077558703256485

9. Phibbs CS, Bhandari A, Yu W, Barnett PG. Estimating the costs of VA ambulatory care. Med Care Res Rev. 2003; 60(3 Suppl):54S-73S. [PMID: 15095546] DOI:10.1177/1077558703256725

10. Smith MW, Joseph GJ. Pharmacy data in the VA health care system. Med Care Res Rev. 2003;60(3 Suppl):92S-123S.

[PMID: 15095548] DOI:10.1177/1077558703256726

11. Wagner TH, Chow A, Barnett PG. HERC's average cost datasets for VA inpatient care FY1998-FY2009 [Internet]. Menlo Park (CA): Health Economics Resource Center; 2010. Available from: http://www.herc.research.va.gov/files/ BOOK_503.pdf

12. Yu W, Wagner TH, Chen S, Barnett PG. Average cost of VA rehabilitation, mental health, and long-term hospital stays. Med Care Res Rev. 2003;60(3 Suppl):40S-53S. [PMID: 15095545] DOI:10.1177/1077558703256724

13. Frakt A. The HCFE state-level Medicaid dataset (version 2005B) [Internet]. Boston (MA): VA Boston Health Care System Research \& Development; 2005. HCFE DD\# 2005-1. Available from:

http://www.hcfe.research.va.gov/docs/ hcfe_mcaid_doc_2005b.pdf

14. Hendricks A (Principal Investigator). VA Extended Care: VA's Experience Under the Millennium Act, January 2003 Report to Congress [Internet]. Bedford (MA): Center for Health Quality, Outcomes and Economic Research; 2003 Nov [cited 2010 Sep 8]. 7 pp. Available from: http://www.hcfe.research.va.gov/docs/PR 2005 02.pdf
15. Ryan J, Super N. Dually eligible for Medicare and Medicaid: Two for one or double jeopardy? Issue Brief Natl Health Policy Forum. 2003;(794):1-24. [PMID: 14524355]

16. Cutler DM, Gruber J. Does public insurance crowd out private insurance? Q J Econ. 1996;111:391-430. DOI:10.2307/2946683

17. Cutler DM, Gruber J. The effect of Medicaid expansions on public insurance, private insurance, and redistribution. Am Econ Rev. 1996;86(2):378-83. [PMID: 10160550$]$

18. Cutler DM, Gruber J. Medicaid and private insurance: Evidence and implications. Health Aff (Millwood). 1997; 16(1):194-200. [PMID: 9018957] DOI:10.1377/hlthaff.16.1.194

19. Gruber J, Simon K. Crowd-out 10 years later: Have recent public insurance expansions crowded out private health insurance? J Health Econ. 2008;27(2):201-17. [PMID: 18206255$]$

20. Pizer SD, Gardner JA. Is fragmented financing bad for your health? [Internet]. Rochester (NY): Social Science Research Network; 2008. Available from: http://ssrn.com/ abstract $=1226522$

Submitted for publication July 31, 2009. Accepted in revised form April 26, 2010.

This article and any supplementary material should be cited as follows:

Hendricks A, Gardner J, Frakt A, Gilden D, Prentice J, Wolfsfeld L, Pizer S. What can Medicaid data add to research on VA patients? J Rehabil Res Dev. 2010;47(8): 773-80.

DOI:10.1682/JRRD.2009.07.0107

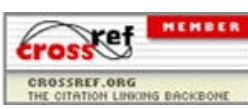

